Arqueología y Sociedad,

№ 23,2011

\title{
LA GUITARRA: UN TROPO ARGUEDIANO
}

Ladislao Landa Vásquez*

\section{Resumen}

Se trata de explorar un tropo arguediano en su novela El Sexto, donde el autor desarrolla muy marginalmente la figura de la construcción de una guitarra, la cual nos sirve para plantear que este instrumento es una expresión de la elaboración de un discurso político social que a la vez es una metáfora de la sociedad peruana.

\section{Palabras clave}

Arguedas, El Sexto, discurso político, sociedad peruana.

\section{Abstract}

This is an exploration about arguedian trope in his El Sexto roman; it is a figure of the marginality construction of guitar, but it is important strategy by Arguedas for elaborated a political discourse and is a metaphor of Peruvian society.

\section{Keywords}

Arguedas, El Sexto, political discourse, Peruvian society.

* Doctor en Antropología por la Universidad de Brasilia (Brasil), Profesor auxiliar de Antropología en la Universidad Nacional Mayor de San Marcos 
Hace algún tiempo inicié una investigación sobre las relaciones de la literatura con la etnografía, y como parte de ésta he explorado la literatura carcelaria. Es cierto que el Perú es un país prolífico en novelas que relatan la experiencia de las cárceles (Hombres y rejas de Juan Seoane; La Prisión de Gustavo Valcárcel), pues motivos no faltaron ni faltan en diferentes épocas para hablar de la represión. Pero en esta ocasión me limitaré a indagar la novela El Sexto de José María Arguedas, donde hallamos temas muy sugerentes. Esta novela que posiblemente tiene menos interés entre los críticos literarios debido a varias razones, y creo entre ellos, por su trama informal, e incluso podríamos decir debido a su argumento algo panfletario, así como por su forma aparentemente trunca. Si bien en esta novela existen varios tópicos que emergen, no obstante, en esta ocasión me gustaría indagar la presencia de un tropo que se desenvuelve muy sutilmente en el texto y que me parece un indicativo que expresa un discurso sobre la situación política del país, se trata de un elemento interesante que los críticos de literatura definirían como índices o iconos que a primera lectura parece desapercibido, en este caso se trata de la mención corta pero recurrente de un instrumento musical, la guitarra.

\section{El SEXTO: LA NOVELA QUE NO PODÍA DEJAR DE ESCRIBIRSE}

Para comenzar, debemos señalar que José María Arguedas escribió El Sexto, pienso, como una promesa consigo mismo, por haber vivido una experiencia carcelaria que marcaría su juventud de una manera dramática, y tal vez agudizaría su depresión. No en vano, señaló en una reunión importante: "cuando estaba estudiando el cuarto año (en la Universidad), uno de los buenos Dictadores que hemos tenido me mando al Sexto, prisión que fue tan buena como mi madrastra, exactamente tan generosa como ella" (Arguedas 1969: 41). En efecto, a la edad de 26 años Arguedas fue enviado a la cárcel cuando estudiaba en la Universidad de San Marcos, donde fue testigo, entre otras cosas, de los debates entre apristas y comunistas. En aquellos años la reacción conservadora fue muy agresiva frente a las protestas sociales, época que fue calificada precisamente como crisis de la República Aristocrática.

De todas las novelas que escribió Arguedas, posiblemente El Sexto es donde trató el tema político de manera central. Esta novela que narra la experiencia carcelaria de Arguedas ocurrida entre 1937-1938, aunque el autor menciona que solo fue escrita entre 1957 y 1960, es decir, 20 años después de los sucesos reales ${ }^{1}$. El Sexto fue publicada finalmente en 1961.

En la novela el narrador, Gabriel, representa a un joven universitario que sufre carcelería en un contexto de luchas sociales (aunque el texto no indica exactamente cuáles fueron las causas reales de su prisión). Los personajes principales que aparecen a lo largo de la novela son varios, pero esta vez solo mencionaremos a algunos de ellos que corresponden a nuestro interés, estos son: Alejandro Cámac Jiménez ("un carpintero de las minas de Morococha y Cerro, ex campesino de Sapallanga" pag. 222); Pacasmayo ("un

1 En una carta a su amigo John Murra, Arguedas manifiesta sus dudas sobre el contexto político en que se publicaría: "No me siento completamente seguro de él en lo que se refiere a las paginas que se refieren a los partidos políticos que padecían una implacable persecución y que tenían por eso a sus mejores hombres en la cárcel. Tengo miedo de ser injusto o exagerado. Ambos partidos -APRA y comunismo- eran entonces, y ahora uno de ellos lo es más aún, rígidos, excluyentes y tan implacables como sus persecutores; pero luchaban por la justicia social; estaban embriagados de mesianismo excluyente. Los amaba y les temía a ambos. Me preocupa sin embargo lo que hago decir a los personajes, porque no se trata ya en este caso de personajes, digamos 'libremente' creados sino de individuos que simbolizan o representan ideologías y métodos de partidos que existen y que han de sentirse retratados y que los lectores han de tomarlos como ejemplos. Creo que es mi deber proclamar la imagen que tengo de esos partidos; pero seré sin duda victima de ambos y de las clases ricas del país. Esto me preocupa únicamente en tanto que pueda constituir un riesgo para la continuación de mi trabajo... Yo hubiera deseado dejar el libro verdaderamente concluido; pero en todo instante me vienen los recuerdos que me obligan a rectificar a veces sólo unas líneas de determinadas página. Y ya he hecho una quinta corrección completa. Lo voy a dejar así. También es probable que nadie quiera publicarlo. En fin, ya veremos eso." (Carta de Arguedas a Murra, 21/2/1961, En Murra y López-Baralt, 1996: 53-54) 
preso sin partido que un diputado había hecho sepultar en el Sexto [...] El diputado lo acusó de comunista porque una mujer a la que ambos cortejaban prefirió a Pacasmayo" p. 252); y el mismo Gabriel que son los que en la novela participan en la construcción de una guitarra.

Veamos:

\section{GUITARRA O METÁFora dE LA POLÍTICA}

En El Sexto, este instrumento musical aparece mencionado solo en 11 ocasiones, pero de manera muy puntual y con referencias muy cortas. Comienza, por ejemplo, cuando uno de los principales personajes, Alejandro Cámac, descubre la sensibilidad de Gabriel (el alter ego de Arguedas) luego de un incidente entre los delincuentes comunes sobre la explotación sexual. Cámac dice: "iMañana empiezo a hacerte una mesa y una guitarra! iNos entretendremos! iPensaremos! IIremos adelante!” (p. 237). Esta escena fortalece a Gabriel quien afirma: "-Cámac, hermanito -le dije-, sé ahora que podré aguantar la prisión" (p. 237).

En realidad, la construcción de la guitarra está asociada a escenas sensibles y de desgarramiento, como si este instrumento se convirtiera en un consuelo y fortaleza para momentos difíciles de la cárcel, pues hallamos expresiones como: "-iHáblame así! Yo te haré tu guitarra; antes de morirme oiré todavía que la tiemplas. Porque yo estoy muy mal por dentro"(p. 274)

Es bueno tomar atención a la sencillez de construcción de la guitarra en esta novela. Este instrumento es construido en la cárcel de restos de un cajón (no se señala el tipo de madera): "se acercó a un cajón que nos servía para sentarnos. De esto voy a hacer una guitarra y una mesa -dijo- iCantaremos en el Sexto!" p. 238)

Hoy, los músicos prestarían atención a este detalle, de seguro dudarán del buen sonido que pueda obtenerse, no es de madera sofisticada como pino báltico o palisandro (que posiblemente era utilizado desde la colonia por los constructores de instrumentos). En la novela, Cámac reconoce que no resultará un gran instrumento, pero aún así, de un madero simple servirá para sobrellevar la prisión. Incluso, debido a la escasez de madera, el constructor admite "iFíjate como avanza la guitarra! Tendrá que ser chica”

En esta novela, Cámac, sufría de tuberculosis, que fue agravado por las constantes torturas, golpizas y encierros a que fue sometido. Por eso, Gabriel tratará de evitar los esfuerzos de su constructor: "iNo te hace mucho daño trabajar? Me dijiste que te sentías morir; lo cual es respondido: "No antes de haber hecho la guitarra y la mesa" (p. 277). La carrera por construir el instrumento es presentado en algunos momentos con cierto dramatismo. Cámac parece competir con la muerte, su objetivo es terminar antes de que la muerte le alcance, por eso el narrador dirá en un momento "Volví a mi celda. Cámac cepillaba, agachado” (p. 280).

En otro pasaje de la novela se muestra a Gabriel muy sensibilizado por la muerte de dos presos mendigos o vagos: el pianista y el japonés. Cámac reconoce que este tipo de sentimiento en un ser humano es difícil de entender, por tanto expresa a Gabriel: "-A ti te hicieron icon qué? Grande vas a tocar la guitarra. Ayúdame. Ya falta poco. Yo también quiero oírte. Tú estás necesitando más. iPuedes alocarte!” (p. 280) La guitarra, entonces, se convierte en una alternativa de salvación del ser humano que está siendo carcomido por la prisión, por la atrocidad de la vida en esos muros, por el grado de inhumanidad a que los presos han llegado. Pero en este proceso, la muerte acecha al constructor de la guitarra y reconoce abiertamente Cámac "-No voy a terminar la guitarra -dijo-. Ahí están las piezas. Ese pobrecito, con el sacrificio, ha recordado los cantos que le habrá oído a su padre" (p. 290). El pobrecito es nada menos que un joven homosexual que está siendo explotado por los taitas de la prisión, y este al cantar vaticina la muerte de Cámac que ocurre en seguida.

Con la muerte de Cámac, la guitarra quedará a medio hacer, cosa que es testimoniado por otra de las víctimas del sistema carcelario, un niño estuprado, Libio Tasaico, que al ser acogido por Gabriel pregunta “iHaces guitarra?” y es respondido "-No, mi compañero de celda, ya se ha ido. No hay quien la termine”. (p. 312). 
Pasará algún tiempo hasta que otro personaje, Pacasmayo o Estremadoyro, al pedir compartir la celda con Gabriel reinicia la construcción: "Oye Gabriel -me dijo-.Ya no me aguantan los compañeros. Somos tres. ¿No me darías un campito aquí? Tú estás solo. Soy curioso, puedo concluir tu guitarra." (p. 316)

En otro pasaje, quizás el más dramático y justiciero de la novela, Pacasmayo ,este continuador en la construcción de la guitarra, se suicida al mismo momento del asesinato de uno de los capos de la prisión, el famoso Puñalada. Como se puede ver, nuevamente queda trunco la construcción del instrumento. Y solo al finalizar la novela, Gabriel narra "Empezó a llover. Encendí mi vela. Descubrí la guitarra a punto de ser concluida, las clavijas ya hechas." (p. 339), lo cual indicaría que solo faltaban unos pocos pasos para finalizar y estos deben ser asumidos por Gabriel, el joven estudiante, el romántico y sentimental personaje que debe darle continuidad a la construcción y la ejecución del instrumento.

Es importante señalar que en esta novela no existe ningún indicativo directo sobre las habilidades musicales de los personajes. No sabemos si Gabriel tocaba este instrumento, tampoco se sabe de Cámac o algún otro personaje. Esto nos muestra un vacío en el encadenamiento y muy poca asociación directa con la trama central. No obstante, el hecho de estar mencionada en determinadas coyunturas de los sucesos de la cárcel nos permite señalar algún objetivo relacionado con un discurso sobre la política.

\section{LA CONSTRUCCIÓN POLÍTICA DE UNA ALTERNATIVA}

Una vez descrito muy escuetamente los lugares más significativos presentados por Arguedas respecto a la metáfora de la guitarra, ahora me gustaría mostrar algunas interpretaciones relacionadas con las ideas políticas que el autor propone. Como ya he señalado, El Sexto posiblemente es la novela arguediana con mayor desarrollo de un discurso político ideológico, y para decir de otro modo, es la presentación de la problemática política ocurrida en la primera mitad del siglo XX, del cual él tomó parte activa, no en vano va señalar que "se refieren a los partidos políticos que padecían una implacable persecución y que tenían por eso a sus mejores hombres en la cárcel" (carta de Arguedas a Murra op. cit.).

La guitarra es un instrumento muy difundido en el Perú y está integrada a diferentes estratos sociales en sus diferentes modalidades, sin embargo, muy poco se ha investigado sobre su uso, exceptuando alguna que otra investigación musicológica ${ }^{2}$. José María Arguedas, nuestro escritor homenajeado en este año, ha mencionado en varias ocasiones tanto en su producción novelística como también en alguno que otro artículo dedicado al folklore. Considero que Arguedas nos ha querido mostrar un mensaje a través del proceso de construcción de un instrumento afín a la sociedad peruana, un instrumento que sin duda fue adoptado en el proceso colonial y que podría servir para expresar algunas ideas.

Si observamos, los primeros esbozos de la guitarra, estos fueron realizados por Cámac, pero debido a su muerte se trunca, aunque luego intenta terminar Pacasmayo (el don Juan apolítico que es dueño de lanchas que está en cárcel por la acusación de un diputado, aunque después se suicida y no logra concluir), dejando con claridad que Gabriel debería continuar en su construcción. El hecho que un obrero minero, Alejandro Cámac, con habilidades de carpintero, se inspirará en la llegada a la cárcel de Gabriel, un joven romántico idealista (además de reconocer su parentesco serrano) es muy importante para el argumento arguediano ${ }^{3}$. Cámac tampoco es un simple personaje en la novela, él representa a un comunista (aunque intuitivo) pero que por su origen también pertenece a una región que para Arguedas fue muy importante.

2 Podríamos mencionar los trabajos de César Santa Cruz, La guitarra en el Perú, bases para su historia (tesis UNMSM); la de de Javier Echecopar, Música para guitarra del Perú.

3 Debemos recordar que existe desde mucho tiempo atrás una especialización en el arte de construcción de instrumentos musicales, y ellos se denominaban ebanistas; hoy están siendo reconocidos por una denominación afrancesada: luthiers. Arguedas posiblemente sabía de la existencia de ebanistas pero asume la idea de que un carpintero y de minas se proponga construir este instrumento. 
En efecto en sus investigaciones etnológicas, su tesis de Bachiller, Arguedas proponía que el centro del Perú, la región de Junín, históricamente representaba a grupos étnicos (en este caso comunidades) que siempre fueron libres, donde no hubo desarrollo de haciendas que pudieran condicionar indios sumisos. Siguiendo estas perspectivas, Cámac representaría a los huancas, indios ideales para procesos de rebelión, capaces de enfrentarse y no doblegarse.

Este cordófono que por supuesto corresponde a la tradición europea -luego introducida a América por los españoles en el periodo colonial, es adoptado muy profusamente en variadas expresiones musicales americanas, así como también en la diversidad del territorio andinopodría representar un modelo de hibridez, así como también la adopción de un elemento cultural de origen europeo.

Y a propósito del desarrollo musical en la época colonial, Arguedas argumentaba en otro trabajo, sobre una distinción entre músicos indios y mestizos: los indios con más frecuencia eran ejecutantes de instrumentos como la quena, arpa y violín, mientras los mestizos preferían la guitarra. Esto se debía, según él, cuando en el proceso de colonización los sacerdotes condenaban la guitarra como un instrumento sensual y lascivo por su forma que se asemejaba al cuerpo de una mujer, por lo cual no permitían que los indios se contaminaran con éste instrumento. Por tanto, la guitarra quedó en manos de mestizos, que posiblemente podían huir a las censuras religiosas y se apropiaron de ella ${ }^{4}$.

Hay que recordar que nuestro novelista gustaba de ejecutar con frecuencia este instrumento,

4 En un artículo sobre el guitarrista Raúl García Zarate publicado en El Comercio (26-VII-1966), Arguedas (1977: 24) decía: "Los españoles prohibieron tocar la guitarra a los indios. Este instrumento fue considerado como "sensual" y peligroso para la conservación de la "inocencia" de los naturales. En cambio, se concedió gracias y exenciones a los arpistas y violinistas. Arpa y violín eran tenidos como instrumentos celestiales. De ese modo, la población nativa, estimulada por las concesiones especiales, se dedicó al cultivo de los instrumentos "puros" que fueron auxiliares de la catequización... La guitarra, en cambio, se convirtió en instrumento distintivo del señor, del misti, weraqocha o caballero..." incluso existen algunas fotografías que lo retratan tocando, asimismo, hoy se ha descubierto más grabaciones donde el novelista canta acompañado con guitarra. En una ocasión pregunté a un profesor sanmarquino que lo conoció y me dijo, que realmente gustaba de tocar, pero "solo rasgaba" afirmó. Sea cual fuere su habilidad con este instrumento, nos dejó algunas evidencias, uno de ellos por ejemplo fue cuando grabó para la musicóloga chilena Margot Loyola en los años '60; este documento fue rescatado y encuentra en los archivos de la Universidad de Chile; y fue traído al Perú por Omar Ponce, musicólogo peruano que nos mostró en una conferencia realizada en homenaje a Arguedas el 3 de diciembre del 2010 en la Universidad de San Marcos. Los otros documentos sonoros son harto conocidos y publicados.

Por otro lado, Arguedas fue un excelente defensor de las expresiones artísticas del ande peruano, un crítico de las tergiversaciones y siguiendo este argumento se podría decir que actuó a veces como un conservador de las expresiones "originales" del arte indígena. Existen varios testimonios de artistas (hoy muy conocidos) que refieren las recomendaciones de Arguedas, quien les "aconsejaba” que no deberían tergiversar su música, sus canciones y danzas; he tenido la ocasión de escuchar a Pastorita Huaracina, Jaime Guardia y Máximo Damián, hacer hincapié sobre estas recomendaciones.

No deseo ahondar en el tema de cuán representativa del mundo andino o cuán colonial y cuán aculturada sea la sociedad peruana en relación a este instrumento; no obstante, si observamos en la obra señalada podemos percibirla como una metáfora que se desenvuelve a través del relato, por tanto me interesa expresar propuestas que pueda ayudar a comprender el discurso de Arguedas sobre la sociedad. En este caso me parece que la guitarra podría representar a un elemento icónico muy importante en el desarrollo de la trama de esta novela. Pienso que Arguedas se apoya en este instrumento por varias razones y posiblemente una de ellas sea la condición artística, sentimental y no racional que pueda asociarse a ella.

No es erróneo señalar que Arguedas en la elaboración de su novela no confía la construc- 
ción de la guitarra a dogmaticos dirigentes comunistas ni menos a fanáticos apristas, sino solo a sensibles e incluso independientes, y hasta cierto punto a apolíticos como Pacasmayo quienes pondrán sus manos sobre este instrumento. ¿Qué podríamos concluir de aquí?

Pienso que en la novela, la alegoría de la guitarra está representando una opción política de Arguedas. La guitarra representa las alternativas de cambio que los políticos podrían haber construido en el Perú del siglo XX, pero en ella deberían haber incluido la sensibilidad andina, la del costeño del norte (por ejemplo la del piurano don Policarpo que se convierte en el justiciero mayor de la prisión). Si nos atenemos a la trama de la novela, observamos que no solo el indio o el blanco son quienes deberían conducir una revolución, también serian los mestizos como Policarpo, los "aculturados" como Cámac, y los blancos con alma de indio como Gabriel quienes tendrían en sus manos las riendas de la revolución.

En efecto, en esta novela se habla de revolución, pues este es el ambiente de los discursos políticos de aquella época. Esta expresión no había sido aún descalificada ni proscrita -como hoy, después de la derrota del socialismo realmente existente. Arguedas como hombre de aquellos tiempos tenía que hablar de revolución. La revolución era un discurso natural y elocuente de ese tiempo, más aún en personas como Arguedas que habían transitado frecuentemente el mundo intelectual y sobre todo universitario.

No obstante, aquí debemos tender hacia una propuesta diferenciada de revolución de nuestro autor. Arguedas se distancia del fanatismo aprista casi religioso, de la entrega dogmatica de los comunistas, proponiendo una guía romántica, sensible a los cambios sociales. Esto no significa, creo, que rechazara abiertamente los discursos ideológicos de ese momento. Está, demás señalar, que en este debate entre aprismo y comunismo, Gabriel-Arguedas siempre se sintió más cerca de los comunistas. Basta recordar que en los momentos más emotivos de la cárcel, Gabriel canta el himno La Internacional, precisamente cuando ocurre la muerte de Cámac, el héroe central de la novela.
Los críticos de literatura han trazado un parámetro para este tipo de análisis al cual han denominado ideología, éste supondría un fondo que sustenta las propuestas de un texto. En el caso de Arguedas, Antonio Cornejo Polar (1989: 131) se ha remitido a las propias declaraciones del autor andahuaylino que había reconocido su influencia mariateguiana y leninista manifestada públicamente en el Encuentro de Escritores de 1968.

Volviendo a la metáfora de la guitarra, no podemos dejar de mencionar que esta manera de reflexionar de Arguedas puede estar asociada con aquellas del líder revolucionario ruso, Lenin, quien en su famoso libro Que Hacer, mencionaba también las condiciones de la revolución, un hecho que supone la acción de aquellos sujetos que habían sufrido en la vida, de aquellos que se habían arrastrado en el barro. La revolución no solo debe ser obra de seres puros o intelectuales que no habían sufrido, sino sobre todo, de quienes sufrían y necesitaban los cambios. La guitarra es también un instrumento que puede pasar por manos barrosas, sucias, pero que se construye con todo los sentimientos.

La política es, entonces, para Arguedas una actividad necesaria aunque difícil de entenderla, ayuda a la justicia, reivindica a los perdedores y se la debe afrontar. Entonces esta guitarra, me parece, igualmente una metáfora de la sociedad y la necesidad de cambio. El cambio se producirá desde perspectivas sencillas, no necesariamente proviene de sofisticados discursos, ella será como la guitarra de restos de una madera abandonada, utilizada en otros menesteres.

Si bien es cierto, este icono puede representar una propuesta discursiva, no obstante, lo que llama la atención también es la inconclusión de la guitarra y en las diferentes manos que va transitando para terminar de construirla. Gabriel, precisamente es el elegido, no porque él se propuso, sino porque siente el deber de continuar, ya que fue iniciado por un sentimental e intuitivo campesino minero huanca (Cámac).

En ocasiones se ha festejado esta independencia de Arguedas y su poca afección a la disciplina partidaria. Esto podría corroborarse con 
una lectura rápida de El Sexto. Por ejemplo, es interesante observar que Cámac insiste en hablar a Gabriel sobre el comunismo, mientras construye la guitarra o habla de ésta, En cambio Gabriel lo interrumpe porque de antemano no está de acuerdo con el comunismo "Pero yo no soy comunista, Cámac; muchos otros participan de los ideales de justicia y libertad, acaso mejor que los comunistas" (p. 274) O cuando el mismo Gabriel responde "-No, Cámac, en eso no estoy de acuerdo. Son muy pocos y fanáticos.” (p. 277).

Evidentemente, Gabriel, personaje narrador de la novela, intenta mantener su neutralidad frente a los dos grandes discursos políticos de esa época, el aprismo y el comunismo, de esta manera estaría expresando estos distanciamientos que luego fueron a veces exacerbados por quienes quisieron interpretar a un Arguedas independiente ${ }^{5}$.

Este discurso arguediano, alternativo ambiguo o tercerista también podría interpretarse como una respuesta a las estrategias cerradas de los militantes políticos de ambos partidos políticos, esta exclusión o rigor disciplinario que no daba lugar a sensibilidades podía haber motivado a esta actitud. La revolución fue pensada como un discurso de valor y entrega por los comunistas, Arguedas tenía que enfrentar ese reto y lo hace a su manera particular, una manera que posiblemente los mismos creadores de estos

5 "Estoy casi seguro de que la publicación de esa novela levantaría contra mi todas las fuerzas poderosas de la política actual del Perú: la derecha, el partido aprista, el partido comunista. Me quedaría con el apoyo de los no muy fanáticos de los tres partidos y con la opinión quizás de los llamados hombres libres. El Sexto fue una prisión política espantosa. Yo estuve allí ocho meses, dos en su antesala (la Intendencia) y dos más en la Sala San Camilo del Hospital '2 de Mayo' que era una cueva tenebrosa. Fui testigo no de torturas físicas sistemáticas, sino de la explosión brutal de algunos oficiales y de los llamados 'soplones' que afrentaban a los presos, con patadas, escupitajos y empellones. En el Sexto, convivíamos presos políticos, asesinos, ladrones, ladronzuelos, vagos y hombres absolutamente inocentes sepultados allí por venganzas personales de quienes tenían poder, especialmente en las provincias. El aspecto más atroz era el de la corrupción sexual que llegaba allí hasta lo infinito." (Carta de Arguedas a Murra, 21/11/1960, En Murra y López-Baralt, 1996: 50) discursos pudieron haber aceptado, no obstante, en ciertas circunstancias estos rigores disciplinarios fueron necesarios, y la cuestión habría consistido en saber distinguir esos momentos. Posiblemente los comunistas cultivaron una tradición de entrega más allá de sus propios límites humanos, aspecto que no pudo haber sido comprendido por algunos, entre ellos por Arguedas. Pensemos en apoteosis novelísticas como Así se templo el acero, que podrían servir de ejemplo para estas inmolaciones. Hoy que la revolución ya no es un tropo bienvenido, tal vez habría que proponer otras formas de construir una guitarra, tal vez a la manera de los músicos contemporáneos y con maderas más adecuadas.

\section{Bibliografía}

Arguedas, José María

1983 Obras Completas, Tomo III. Editorial Horizonte, Lima: 217-344

1969 "Intervención de José María Arguedas", En Primer Encuentro de Narradores Peruanos. Casa de la Cultura del Perú, Lima: 36-46.

1977 Nuestra música popular y sus intérpretes, Lima: Mosca Azul \& Horizonte Editores.

Cornejo Polar, Antonio

1989 La novela peruana, Lima: Editorial Horizonte.

Murra, John V.; Mercedes Lopez-Baralt (ed.)

1996 Las cartas de Arguedas, Lima: Fondo Editorial de PUCP.

Rowe, William

1979 Mito e ideología en la obra de José María Arguedas. Lima: Instituto Nacional de Cultura. Cuadernos del INC 3. 